\title{
Relações internas na família linguística Tupí-Guaraní
}

\author{
Aryon Dall'Igna Rodrigues
}

O propósito deste trabalho é apresentar uma subdivisão da família linguística Tupí-Guaraní com base no conhecimento que atualmente temos dela. Embora o conhecimento das línguas Tupí-Guaraní tenha aumentado consideravelmente nos últimos 25 anos, desde a publicação de minha classificação anterior (Rodrigues 1958a, b), sobretudo devido à documentação e análise de grande número de línguas, não está, entretanto ainda suficientemente desenvolvido de modo a poder-se lançar mão de todos os aspectos fonológicos, gramaticais e lexicais das diversas línguas. A maior parte dos resultados dos estudos realizados neste quarto de século continua inédita e, por isso, pouco disponível para a pesquisa comparativa. Por essa razão, a proposta aqui apresentada se baseia numa seleção limitada de elementos fonológicos e lexicais, com recurso apenas marginal a informações gramaticais, e tem caráter necessariamente provisório. Não obstante, acredito que a presente proposta oferece bastante consistência do ponto de vista da linguística histórica e que poderá revelar-se útil como um modelo hipotético de desmembramento histórico das línguas e, em certa medida, dos povos Tupí-Guaraní, a ser testado não só pelos linguistas, mas sobretudo também pelos antropólogos, em vista de argumentos sociais e culturais.

Preliminarmente, quero referir-me brevemente às noções de parentesco linguístico genético e de protolíngua. Duas ou mais línguas são consideradas geneticamente aparentadas quando compartilham propriedades estruturais e lexicais tais e tantas, que, em seu conjunto, não se possam explicar nem como consequências independentes de princípios universais da linguagem, nem como resultado de um processo de aquisição pelos falantes de uma língua em eventual interação social com os falantes de outra; a hipótese que se põe, então, é a de que as línguas em questão sejam manifestações diferenciadas do que foi no passado uma mesma língua e que as propriedades compartilhadas 
sejam a herança comum conservada sem diferenciação ou apenas com diferenciações menos profundas.

Esta hipótese se baseia em duas propriedades conhecidas das línguas em geral: (a) toda língua está em constante mudança e (b) as mudanças numa comunidade linguística não coincidem necessariamente com as mudanças em outra comunidade. Desde o momento em que uma comunidade se divide em duas, com consequente interrupção parcial ou total da comunicação entre os membros dos dois segmentos, começa a haver mudanças linguísticas descoincidentes em cada um destes, as quais passam a caracterizar um processo diferencial crescente. O maior ou menor grau de diferenciação observável entre as línguas em dado momento é basicamente uma função do tempo decorrido entre o início do processo - a cisão da comunidade original - e o momento da observação. O processo de cisão pode repetir-se algum tempo depois, afetando qualquer das línguas resultantes. Os termos dialeto, (língua da mesma) família, (língua do mesmo) tronco, (língua do mesmo) filo são usados pelos linguistas para indicar diversos graus de diferenciação. Esses termos implicam, portanto, diferentes profundidades temporais entre o momento da observação e a língua comum original tomada em consideração. Essa língua comum em cada caso considerado é o que se chama de protolíngua. A protolíngua de um filo tem profundidade temporal maior que a de um tronco, a profundidade temporal da protolíngua de um tronco é maior que a da protolíngua de uma família, e a profundidade temporal da protolíngua de uma família é maior que a da protolíngua de um grupo de dialetos.

Esse modelo de multiplicação de línguas por cisão de comunidades linguísticas não esgota os casos de surgimento de novas línguas. Um caso complementar é o da interação de duas línguas numa mesma comunidade - bilinguismo - com subsequente redução a uma só língua com propriedades dominantes de uma das duas, mas com características devidas à outra. Diferentes situações sociais podem dar lugar a uma grande variedade de relações entre duas línguas num contexto bilíngue, levando a resultados bastante diversos quando da redução do bilinguismo a uma só língua. Qualquer família linguística pode incluir línguas que tenham resultado de um processo dessa natureza.

A classificação das línguas dos povos Tupí num tronco Tupí que abrange diversas famílias deve ser entendida como refletindo esse modelo genético. As línguas das famílias Tupí-Guaraní, Tuparí, Mondé, Aríkém, Ramaráma, Mundurukú e Jurúna provêm de protolínguas (Proto-Tupí-Guaraní, etc.), as quais, por sua vez, são oriundas de uma protolíngua mais remota, o Proto-

1. Algumas reconstruções de palavras do Proto-Tupí publiquei em Hanke, Swadesh e Rodrigues 1958; algumas outras em Rodrigues 1966 e 1980. 
-Tupíi ${ }^{1}$. Além das famílias mencionadas, o tronco Tupí é integrado também pelas línguas Awetí, Mawé (Sateré) e Puruborá, as quais não se filiam imediatamente a nenhuma família em particular (ou, o que no fundo é a mesma coisa, são membros únicos de três famílias adicionais).

Até agora tanto o Awetí quanto o Mawé vinham sendo incluídos na família Tupí-Guaraní (Rodrigues 1958a, b, 1971). O melhor conhecimento de ambos (para o Awetí v. Emmerich e Monserrat 1972, Monserrat 1976; para o Mawé vários manuscritos de A. e S. Graham, Summer Institute of Linguistics, Brasília), deixa claro, entretanto, que são tão aberrantes, cada um a sua maneira, em relação a todas as outras línguas incluídas naquela família, que sua associação com elas deve ser procurada num outro plano. Sua exclusão da família Tupí-Guaraní permite ter nesta um conjunto consideravelmente homogêneo de línguas, cuja comparação em detalhe pode ser realizada mais abrangentemente em todos os aspectos da estrutura linguística, o que por sua vez permite empreender a reconstrução da respectiva protolíngua a partir de uma base mais sólida. Por outra parte, a inegável maior afinidade que o Awetí e o Mawé mostram com a Tupí-Guaraní deve levar à postulação de (pelo menos) uma protolíngua intermediária entre o Proto-Tupí e o Proto-Tupí-Guaraní, a menos que as características Tupí-Guaraní de qualquer deles se revele resultante de um processo de contacto linguístico (o Mawé apresenta acentuada influência lexical da Língua Geral Amazônica, que deve ter-se desenvolvido nos séculos XVII, XVIII e XIX, mas não é seguro que suas outras características Tupí-Guaraní sejam tão recentes; o Awetí, por sua vez, mostra influência lexical do Kamayurá, mas ainda não é possível avaliar as relações históricas entre esses dois idiomas Tupí que foram encontrar-se no Alto Xingu).

As línguas da família Tupí-Guaraní compartilham um grande número de propriedades, tanto de estrutura como de léxico. Destas seleciono algumas como diagnósticas não só para efeito de inclusão de uma língua na família, mas também para exclusão de línguas geneticamente aparentadas, porém em nível mais remoto: ${ }^{2}$

2. Para facilitar a composição tipográfica, evita-se neste trabalho o emprego de alguns símbolos fonéticos não disponíveis. Para tanto, adotaram-se as seguintes convenções: $y$ é usado para a vogal alta central não arredondada; $j$ para o $i$ assim como para a fricativa álveo-palatal sonora; $d j$ para a africada álveo-palatal sonora; $x$ para a fricativa álveopalatal surda; $t$ s para a africada alveolar surda; $t x$ para a africada álveo-palatal surda; $n g$ para a nasal velar; $b$ para a fricativa bilabial sonora; $f$ para a fricativa bilabial surda; 'para a oclusiva glotal. Um asterisco $\left(^{*}\right)$ marca, como é usual, fonemas e palavras reconstruídos de uma protolíngua. 
(a) Prefixos marcadores de sujeito comuns aos verbos intransitivos e transitivos em orações independentes, incluindo formas iguais a, ou deriváveis fonologicamente de: $a$ - "eu", ere- "você", ja- "eu e você", oro- "eu e ele", pe- "você e ele", o- "ele, eles" (também "eu, você e ele").

(b) Pronomes pessoais exprimindo possuidor, sujeito de verbos descritivos e objeto direto, assim como sujeito de verbos intransitivos em orações dependentes, incluindo formas iguais a, ou deriváveis fonologicamente de: (i) txé "eu", (e) né "você", jané "eu e você", oré "eu e ele", pe (ẽ) "você e ele" (também atxé "eu, você e ele").

(c) Prefixos relacionais incluindo $r$-, que assinala que o determinante da palavra prefixada é a palavra que a precede imediatamente, aplicável a uma classe de palavras que inclui "olho", "rosto", "lábio inferior", "sangue", "corpo", "folha", "casa", "nome"; p. ex., Tupinambá payé r-esá "olho do pajé", xe r-esá "meu olho".

(d) O fonema $j$ (ou equivalente álveo-palatais ou alveolares; $t x, d j, \tilde{n}, z$ ) em palavras como jatxý "lua", jakú "jacu", jý "machado", jurú "boca", ajurú "papagaio", já’ẽ "vasilha de barro", kujã "mulher", júb "amarelo", pajé "xamã", реju "soprar".

(e) O fonema $t x$ (ou $t s, s, h$ ou zero) em palavras como txý "mãe", txók "larva", -txu'u "morder, mastigar", -watxú, -utxú "grande", -ubitxáb "grande, importante, chefe", txám "corda", -etxá "olho", txo’o "animal de caça".

(f) O fonema ts (ou s, $h$, ou zero) em palavras como tsó "ir", tsetá "são muitos", otsenúb "ele o ouve", pytsatsú "novo", potsáng "remédio", pytsyk "pegar", pytsá- "noite".

(g) As palavras itá "pedra" e eír "mel, abelha" com i (e não wi, im kwi ou $k y)$.

(h) Vocabulário básico incluindo formas deriváveis fonologicamente de: jatxý "lua", ybák "céu", -atá "fogo", jepe’áb "lenha", ybyrá "pau", -apó "raiz", ka’á "mato", -etxá "olho", tĩ "nariz, bico", jurú "boca", nmí "orelha", jybá "braço", poti'á "peito", -etymã "(canela da) perna", -o’ó "carne", abá "pessoa, quem?", ma’é "coisa, que?", pirá "peixe", wyrá "ave", kuyã "mulher", pukú "comprido", poráng "bonito", -obý "verde/azul", péb "baixo, chato, plano", mokõy "dois", manõ "morrer", me’éng "dar", je’éng "falar", apó "fazer", atá "andar", -epják "ver", ma’ẽ "olhar".

(i) A palavra petým (e não pé) "fumo, tabaco" (literalmente "tabaco plantado").

Esse conjunto de características poderia ser ampliado, mas mesmo assim restrito parece suficiente para a identificação de qualquer língua como membro da família Tupí-Guaraní, assim como para a exclusão de quaisquer outras línguas. Uma enumeração ampla, ainda que não exaustiva, das línguas que constituem a família Tupí-Guraní é a seguinte: Amanayé, Anambé, Apiaká, Araweté, Asuriní do Tocantins (Akuáwa), Asuriní do Xingu, Avá (Canoeiro), 
Chiriguano (Ava), Emérillon, Guajá, Guajajára, Guraní Antigo, Guraní Paraguaio, Guarayo (Guarayú), Guayakí (Aché), Horá (Jorá), Izoceño (Chané), Kaiwá (Kayová, Pãi), Kamayurá, Kayabí, Kokáma, Kokamíya (Cocamilla), Língua Geral Amazônica (Nheengatú), Língua Geral Paulista (Tupí Austral), Mbyá (Guaraní), Ñandéva (Txiripá), Omágua, Parakanã, Parintintín, Sirionó, Suruí (Majetíre), Takunyapé, Tapieté, Tapirapé, Tembé, Tupí-Kawahíb (Tupí do Machado, Pawaté, Wiraféd, etc.), Tupinambá, Turiwára, Urubú, Wayampí, Wayampipukú, Xetá (Serra dos Dourados).

Dentro desse conjunto de umas quarenta línguas Tupí-Guaraní podem distinguir-se subconjuntos segundo o compartilhamento de certas propriedades mais específicas, que podemos estabelecer com referência ao Proto-Tupí-Guaraní. As propriedades escolhidas são basicamente fonológicas e sua seleção se deve essencialmente à experiência pessoal do autor na observação comparativa das línguas desta família, mas também ao fato de que são propriedades mais facilmente identificáveis nos dados presentemente disponíveis. Outras propriedades fonológicas e grande parte das propriedades gramaticais e lexicais não podem ainda ser utilizadas comparativamente para todo esse amplo conjunto de línguas, devido à insuficiência da documentação. Por exemplo, o item lexical para "morcego" confirma a distinção entre os subconjuntos I e II: tanto no Guaraní Antigo, quanto em línguas Guaraní modernas, como o Guaraní Paraguaio, o Mbyá e o Xetá, o morcego é designado por mopí, ao passo que no Guaráyo é anýra, termo que corresponde a anyrá usado no Tupinambá do subconjunto III, no Tembé do subconjunto IV e no Parintintín do subconjunto V; anyrá ocorre também em Guaraní, mas aí designa uma espécie de pássaro, situação inversa à do Guarayo, onde mópi é que é nome de pássaro. Entretanto, ainda não é possível acompanhar a distribuição desses dois nomes em todo o domínio Tupí-Guaraní.

São os seguintes os sete subconjuntos propostos aqui tentativamente:

\section{Subconjunto I}

Características mais gerais em relação ao PTG:

(a) perda das consoantes finais;

(b) conservação de *tx ou sua mudança em $t s$ ou $s$;

(c) mudança de *ts em $h$ ou zero;

(d) mudança de em * pw em $k w$ ou $k$;

(e) mudança de * $p j$ em $t x$ ou $x$.

\section{Línguas e/ou dialetos:}

Guaraní Antigo

Mbyá

Xetá (Serra dos Dourados) 
Ñandéva (Txiripá)

Kaiwá (Kayová, Pãi)

Guaraní Paraguaio

Guayakí (Aché)

Tapieté

Chiriguano (Ava)

Izoceño (Chané)

Exemplos: (a) PTG *aipotár "eu o quero", Mbyá aipotá; (b) PTG *jatxý "lua", Mbyá datxý; (c) PTG *otsó "ele vai", Guaraní Antigo ohó, Mbyá oó; (d) PTG *opweráb "ele se recupera", Mbyá okwerá; (e) PTG *atsepják "eu o vejo", Mbyá aetxá.

\section{Subconjunto II}

Características mais gerais em relação ao PTG:

(a) perda das consoantes finais;

(b) fusão de *tx e *ts, ambos manifestos por ts ou $s$;

(c) mudança de * $p w$ em $k w$ ou $k$;

(d) conservação de * $p j$;

(e) deslocamento do acento da última para a penúltima sílaba da palavra.

\section{Línguas e/ou dialetos:}

Guarayo (Guarayú)

Sirionó

Horá (Jorá)

Exemplos: (a) PTG *aipeték "eu bato nele", Guarayo aipéte; (b) PTG *jatxý "lua", Guarayo játsy; PTG *otsó "ele vai", Guarayo ótso; (c) PTG *apweráb "eu me recupero", Guarayo akwéra, Sirionó akéra; (d) PTG *atsepják "eu o vejo", Guarayo atsépja; (e) PTG *pirá "peixe", Guarayo píra.

\section{Subconjunto III}

Características mais gerais em relação ao PTG:

(a) conservação das consoantes finais;

(b) fusão de *tx $\mathrm{e}^{*} t s$, ambos manifestos como ts ou $s$;

(c) conservação de * $p w$;

(d) conservação de * $p$;

(e) conservação do acento.

\section{Línguas e/ou dialetos:}

Tupinambá

Língua Geral Paulista (Tupí Austral)

Língua Geral Amazônica (Nheengatú) 
Kokáma

Kokamíya (Cocamilla)

Omágua

Exemplos: (a) PTG *aipotár "eu o quero”, Tupinambá aipotár; (b) PTG *jatxý "lua", Tupinambá jasý; PTG *otsó "ele vai", Tupinambá osó; (c) PTG *opweráb "ele se recupera", Tupinambá opweráb; (d) PTG *atsepják "eu o vejo", Tupinambá asepják; (e) PTG *pirá "peixe", Tupinambá pirá.

\section{Subconjunto IV}

Características mais gerais em relação ao PTG:

(a) conservação das consoantes finais, com ou sem modificações;

(b) fusão de *tx e *ts, ambos mudados em $h$;

(c) mudança de * $p w$ em $k w$;

(d) mudança de * pj em $t x$ ou $t s$;

(e) mudança de *j em $t x, t s, s$ ou $z$.

\section{Línguas e/ou dialetos:}

Tapirapé

Avá (Canoeiro)

Asuriní do Tocantins (Akuáwa)

Suruí do Tocantins (Majetíre)

Parakanã

Guajajára

Tembé

Exemplos: (a) PTG *oker "ele dorme”, Tembé okér, Asuriní do Tocantins óken, Parakanã oken; (b) PTG *jatxý"lua", Tembé zahý, Asuriní do Tocantins txahýa, Parakanã txaýa, Tapirapé txãhý; PTG *otsó "ele vai", Tembé ohó, Asuriní do Tocantins áha; (c) PTG *opweráb "ele se recupera", Tembé okweráw; (d) PTG *atsepják "eu o vejo", Tembé aetsák, Asuriní do Tocantins aétxang; (e) PTG *jakaré "jacaré", Tembé zakaré, Asuriní do Tocantins txakare, Tapirapé txãkãré.

\section{Subconjunto V}

Características mais gerais em relação ao PTG:

(a) conservação das consoantes finais;

(b) fusão de *tx e *ts, ambos mudados em $h$ ou zero;

(c) mudança de * $p w$ em $f$ (bilabial);

(d) mudança de * pj em $s$;

(e) mudança de * $j$ em $d j$;

(f) marcas pronominais de $3^{a}$ pessoa masculina, feminina e plural.

Línguas e/ou dialetos: 
Kayabí

Asuriní do Xingu

Araweté (?)

Exemplos: (a) PTG *akér "eu durmo", Kayabí aset, Asuriní do Xingu akit; (b) PTG *jatxý "lua", Asuriní do Xingu djahy; PTG *otsó "ele vai", Kayabí oó, Asuriní do Xingu aha; (c) PTG *tseapwén (ou *tsyapwán) "cheira bem", Asuriní do Xingu heafen; PTG *-akypwér "parte de trás", Kayabí -akyfér-a "rastro"; (d) PTG *otsepják "ele o vê", Kayabí wesák, Asuriní do Xingu oesak; (e) PTG "jakaré "jacaré", Kayabí jakaré, Asuriní do Xingu djakaré; (f) Kayabí 'nga pý "pé dele" (homem falando), kĩa pý "pé dele" (mulher falando), ẽẽ pý "pé dela" (h. f.), kỹna pý "pé dela" (m. f.), 'ngã pý "pés deles, delas" (h. f.), wã pý "pés deles, delas" (m. f.)

\section{Subconjunto VI}

Características mais gerais em relação ao PTG:

(a) conservação das consoantes finais;

(b) fusão de *tx e *ts, ambos mudados em $h$;

(c) mudança de * $p w$ em $k w$ (Parintintín, Apiaká) ou em $f w, f$ (Tupí-Kawahíb);

(d) conservação de * $p$;

(e) conservação de * $j$;

(f) marcas pronominais de $3^{\text {a }}$ pessoa masculina, feminina e plural, comuns ao homem e à mulher.

\section{Línguas e/ou dialetos:}

Parintintín (Kagwahíb)

Tupí-Kawahíb (Tupí do Machado, Pawaté, Wiraféd, etc.)

Apiaká (?)

Exemplos: (a) PTG *akér "eu durmo", Parintintín akír; (b) PTG *jatxý "lua", Parintintín jahý; PTG *otsó "ele vai", Parintintín ohó; (c) PTG *tseapwén "cheira bem", Parintintín heakwén; PTG *-akypwér "parte de trás", Parintintín -akykwér-i "na ausência"; (d) PTG *-epják "ver", Parintintín apiag; (e) PTG *jacaré "jacaré", Parintintín jakaré; (f) Parintintín ga pý "pé dele", hẽ pý "pé dela", nga pý "pés deles, delas".

\section{Subconjunto VII}

Características mais gerais em relação ao PTG:

(a) conservação das consoantes finais;

(b) fusão de *tx e *ts, ambos mudados em $h$ ou zero;

(c) mudança de * pw em $k w$ ou $h$; 
(d) conservação de * $p j$ em $t s$;

(e) conservação de * $j$;

\section{Língua:}

Kamayurá

Exemplos: (a) PTG *akér "eu durmo", Kamayurá akét; (b) PTG *jatxý "lua", Kamayurá jaý; PTG *otsó "ele vai", Kamayurá ohó; PTG * pytsatsú "novo", Kamayurá pyaú; (c) PTG *-pwár "amarrar", Kamayurá - hwat; (d) PTG *-epják "ver", Kamayurá -etsák; (e) PTG *jacaré "jacaré", Kamayurá jakaré.

\section{Subconjunto VIII}

Características mais gerais em relação ao PTG:

(a) perda parcial das consoantes finais;

(b) fusão de ${ }^{*} t x$, ambos mudados em $h$ ou zero;

(c) mudança de * $p w$ em $k w$;

(d) mudança de * $p j$ em $s$;

(e) conservação de ${ }^{*} j$;

\section{Línguas e/ou dialetos:}

Takunyapé

Wayampí (Oyampí)

Wayampipukú

Emérillon

Amanayé

Anambé

Turiwára

Guajá

Urubú

Exemplos: (a) PTG *akér "eu durmo", Urubú akér, Wayampí áke; PTG * potýr "flor", Urubú putýr, Wayampí póty, Wayampipukú potyr, (b) PTG *jatxý "lua", Urubú jahý, Wayampí jáy; PTG *otsó "ele vai", Urubú ohó, Wayampí óo; (c) PTG *-pwár "amarrar", Urubú -kwa; PTG *-pópwár "amarrar as mãos", Urubú pukwár, (d) PTG *-epják "ver", Urubú -sak, Wayampí -ésa "achar"; (e) PTG *jacaré "jacaré", Urubú jakaré, Wayampí jakaré.

No subconjunto I temos uma língua documentada já há 350 anos, o Guaraní Antigo (da Província de Guairá de Montoya 1639, 1640) e do rio Uruguai (Aragona 1979), e as diversas variedades do Guaraní moderno, nenhuma das quais se pode afirmar que seja a continuação direta daquela. Fora o Guaraní Paraguaio, cujo uso se generalizou no Paraguai e no nordeste da Argentina durante o período colonial, o candidato mais provável a descendente do 
Guaraní Antigo parece ser o Ñandéva (Txiripá, Apapokúva). O Mbyá mantém ainda hoje um traço fonológico mais conservador que o traço correspondente do Guaraní Antigo - o fonema tx, oriundo do PTG * $t x$ o qual é $t s$ no Guaraní Antigo. O Xetá da Serra dos Dourados no noroeste do Paraná, embora muito diferenciado em diversas propriedades fonológicas e lexicais, está, quanto a suas características diagnósticas, ligado mais intimamente ao (Xetá ne txo "morderam-te", Mbyá ne mas txu’ú, mas Kaiwá ne su’ú, Guaraní Antigo ne tsu'ú). Já o Chiriguáno mais provavelmente separou-se de um ancestral comum ao Mbyá e ao Guaraní Antigo, portanto algum tempo antes da documentação deste último. O Izoceño é um dialeto do Chiriguáno falado por descendentes dos índios Chané, originalmente de língua da família Aruák. O mesmo se dá com o Tapieté, falado por um povo chaquenho provavelmente de origem Matáko. O Guayakí (Aché), mais fortemente alterado na sua estrutura gramatical, coparticipa das propriedades diagnósticas deste subconjunto, aproximando-se mais particularmente do Mbyá (Guayakí txu'ú "morder", Mbyá txu’ú; Guayakí pytxý "pegar", Mbyá pytxý; Guayakí raá, ráa "levar", Mbyá araá "eu levo", etc.)

O subconjunto II, situado tão mais ao norte do subconjunto I, compartilha com este uma grande quantidade de propriedades, mas diferencia-se em alguns traços importantes. Os mais notáveis destes são a não transformação de * $t$ em $h$ e a não mudança de * $p j$ em $t x$, conservadorismos que o Guarayo e o Sirionó têm em comum só com o geograficamente longínquo subconjunto III, em que se incluem o Tupinambá da costa atlântica e o Kokáma do alto Amazonas (PTG *otsó "ele vai", Guarayo ótso, Sirionó óso, Tupinambá osó, Kokama útsu, em contraste com o Guaraní Antigo ohó, Chiriguáno ohó, Mbyá oó); PTG *-epják 'ver', Guarayo -épja, Sirionó -éa [proveniente intermediariamente de *épa, com queda regular de p], Tupinambá -epják, em contraste com o Guaraní Antigo - etxág, Chiriguáno -éxa, Mbyá -étxá. O Sirionó, embora fortemente alterado a ponto de justificar a hipótese que reiteradamente tem sido levantada de tratar-se de língua falada por um povo originalmente não Tupí, que teria sido Guaranizado, revela-se mais imediatamente ligado ao Guarayo, fato que casa bem com a situação geográfica dos dois. O Horá é o dialeto mais setentrional do Sirionó.

No subconjunto III, além do Tupinambá documentado nos séculos XVI e XVII (Staden 1557, Léry 1578, Anchieta 1595, Araujo 1618, etc.), acrescento as duas línguas gerais, que são suas descendentes diretas: a Paulista, que é o "Tupí Austral" de Martius (1867:99-122), e a Amazônica ou Nheengatú, melhor conhecida que aquela e ainda hoje falada (Magalhães 1876, Tatevin 1910, Stradelli 1929, Silva 1961, etc.). Acrescento também o Kokáma (com o qual o Kakamíya e o Omágua são quase idênticos) porque este, apesar de fortemente diferenciado em sua gramática, é diretamente derivável de formas como as 
do Tupinambá (por exemplo, Kokáma tsaíri "raiado", Tupinambá sa'ír "está raiado"; Kokáma tsúni "ser preto", Tupinambá sún "é preto"; Kokáma játsy "lua", Tupinambá jasý; Kokáma jáu "chaga", Tupinambá já’ó, etc.). Como o Kokáma apresenta certas propriedades importantes não Tupí, dá a impressão de tratar-se de mais um caso de língua Tupí-Guaraní adotada por um povo não Tupí. Um dos fatos mais interessantes do Kokáma a esse respeito é que ele tem diferentes pronomes pessoais segundo o sexo do falante, e em dois casos o pronome dos homens é não Tupí, ao passo que o pronome das mulheres é correlacionável com o Proto-Tupí-Guaraní (e, portanto, com o Tupinambá): "eu ơ" é ta (não Tupí), mas "eu q" é étse (PTG *itsé, Tupinambá isê); "ele/ela o" é úri (não Tupí), mas "ele/ela q" é ái (PTG, Tupinambá *a’é, "esse de que você fala"). Os pronomes referentes ao interlocutor têm uma só forma para os dois sexos, e essa é Tupí-Guaraní: "você" éne (Tupinambá enê), "nós inclusivo (eu e você)" íni (Tupinambá yanê), "vocês" épe (Tupinambá pé, pe’ê). Para "nós exclusivo" há também duas formas, mas nenhuma delas é de origem Tupí: tánu ô, pénu , em contraste com PTG *oré, Tupinambá oré.

Foi levantada a hipótese de que os Kokáma seriam um povo Tupí-Guaraní oriundo do Baixo Amazonas, o qual teria migrado para o Alto Amazonas. A língua Kokáma não pode ser imediatamente associada nem com as línguas do subconjunto VIII, que mais propriamente poderia ser considerado como baixo-amazônico (ao contrário desse subconjunto o Kokáma não mudou *tx e *ts em $h$ ou zero: Kokáma játxy "lua", mas Turiwára jahý, Amanajé jahír, Wayampí jáy; Kokáma kwarátxi "sol", Turiwára kwarahý, Amanajé kwarahý, Wayampí kwaráy), nem com as línguas dos subconjuntos IV (TocantinsAraguaia), V (Médio Xingu) e VI (Tapajós-Madeira) (Tembé zahý e kwarahý, Asuriní do Xingu djahý e kwarahý, Parintintín jahý e kwarahý). Ela compartilha mais propriedades fonológicas com o Tupinambá: além do Tupinambá jasý "lua" e kwarasý; "sol", considere-se também a manutenção da articulação labial em Kokáma tsakapýry "depois de", e Tupinambá sakypwéri "atrás dele", provenientes do $\mathrm{PTG}$ *tsakypwéri, em contraste com o Parintintín hakykwéri "em sua ausência", o Tembé haykwé-pe, haykwér-amo "atrás dele", etc., em que a consoante labial * $p$ do PTG foi substituída pela consoante velar $k$ diante de $w$.

Se o Kokáma tivesse evoluído mais ou menos independentemente de maiores interferências de línguas não Tupí-Guaraní, ele deveria ser considerado como mais afim ao Tupinambá, mas mais conservador que este quanto a pelo menos uma propriedade do Proto-Tupí-Guaraní, pois ele apresenta sistematicamente $t s$ (ou $t x$ diante de $i$ ) como reflexo de * $t x \mathrm{e}^{*} t s$, enquanto que o Tupinambá tem $s$ (ou $x$ depois de $i$ ). Entretanto, como há fortes indicações de que o Kokáma deve ter resultado da interação entre uma língua Tupí-Guaraní e uma língua de outra filiação (ainda não identificada), é possível que $t s$ (e $t x$ ) 
tenham substituído $s$ (e $x$ ) por serem fonemas existentes nessa outra língua (note-se, entretanto, que o Omágua (Tessmann 1930) apresenta se $x$ : jáse "lua", koaraxi "sol"). Assim sendo, não deve desprezar-se a possibilidade de que o Kokáma resulte da migração de um povo que falasse uma língua muito mais próxima do Tupinambá.

No subconjunto IV reúnem-se o Tapirapé e o Asuriní do Tocantins, que além dos traços fonológicos mencionados acima têm outros em comum, e o Guajajára e o Tembé, que são praticamente dois dialetos de uma mesma língua. Incluo também o Avá ou Canoeiro: registro feito há poucos anos (1974) por Harrison (ms.) de uma amostra de sua língua, embora limitado, é suficiente não só para sugerir sua associação com este subconjunto, mas sobretudo para rejeitar a velha hipótese segundo a qual os Ava seriam descendentes de índios Karijó levados de São Paulo a Goiás por uma bandeira. A manutenção sistemática das consoantes finais exclui a possibilidade de tratar-se de uma língua do subconjunto I (Guaraní): PTG "ele dorme", Avá óker, Asuriní do Tocantins óken, mas Guaraní oké; PTG *amán "chuva", Avá áman, Asuriní do Tocantins ámyn, mas Guaraní amã; PTG * maníóka "mandioca", Avá mánióka, Asuriní do Tocantins mani'ánga, mas Guaraní mani'ó; PTG *jawár "onça", Avá txáwar "cachorro", Asuriní do Tocantins txawar-, mas Guaraní djagwá; PTG *jepe’áb "lenha", Avá txepéaw, mas Guaraní djepe’á.

Além da manutenção das consoantes finais (e também do sufixo nominativo - $a$, que se vê acima em mánióka e que aparece também em outros nomes, como mbóya "cobra", "casa"), o Avá tem em comum com o Asuriní do Tocantins e o Tapirapé também a mudança de *jem tx (Tapirapé txãwãrã "cachorro", txepe'ãwã "lenha") e com o mesmo Asuriní o deslocamento do acento para a esquerda, fatos fonológicos pelos quais também se distingue do Guaraní (particularmente dos dialetos orientais do Guaraní, entre os quais se acharia o Karijó; os dialetos ocidentais, do Chaco boliviano, como o Chiriguáno, também apresentam o acento deslocado para a esquerda). Enquanto no Guaraní *tx do PTG é $t x$, ts ou s (conforme o dialeto: Mbyá djatxy, Guaraní Antigo jatsý, Guaraní Paraguaio djasý), no Avá ele se converte em zero, oriundo de h, como em Asuriní do Tocantins e em Tapirapé: Avá txáy "lua", Asuriní do Tocantins txahy-, Tapirapé txãhý.

A suposição de que a língua dos Canoeiro ou Avá seria um dialeto Guaraní e confirmaria a hipótese de que os Canoeiros seriam descendentes de Karijó fugidos para o sertão foi manifestada primeiro por Couto de Magalhães em 1863, ao publicar umas cinquenta palavras daqueles índios (Magalhães 1946:100-101); depois foi reapresentada por Nimuendajú (1914) e por Rivet (1924), com base nos mesmos dados de Couto de Magalhães. Visto que mais de cem anos se passaram do registro de Couto de Magalhães até o (re)descobrimento dos atuais Avá e o registro de Harrison, poderia pensar-se que 
talvez os Canoeiros referidos no século passado não sejam os mesmos que os atuais Avá. Um confronto da lista de palavras de Couto de Magalhães com a de Harrison fala, entretanto, em favor de uma identidade. Também em Couto de Magalhães aparecem palavras mantendo as consoantes finais e o sufixo nominativo: ará "sol" (Harrison ár), ocá "casa" (Harrison óka), uvá "flecha" (cf. Asuriní do Tocantins o'ywa). Para a "banana" o Avá (Harrison) tem um nome que não se encontra em outras línguas: maéapar (o que significa literalmente "coisa recurvada"); pois esse mesmo nome já aparece na lista de Couto de Magalhães: manapary (em que $n$ deve ser erro tipográfico por $e$ ). Também o nome para "machado" tem uma forma característica no Avá atual, txywár (da raiz PTG *jý), a qual igualmente já se encontra naquela velha lista: dgigua (uma aproximação gráfica de (r)). Concluímos que a língua dos Canoeiro de Couto de Magalhaes era essencialmente a mesma que a dos atuais Avá, a qual é nitidamente distinta dos dialetos Guaraní, entre os quais se situaria a língua dos antigos Karijó.

Uma outra hipótese que poderia ser aventada é a de que os Karijó incorporados às bandeiras nos séculos XVII e XVIII não falassem mais seu dialeto Guaraní, mas usassem a Língua Geral Paulista (“Tupí Austral”), a qual, como vimos, descendia do Tupinambá. Esta hipótese não encontra, porém, apoio nos dados fonológicos e lexicais, que não permitem identificar os Avá como falantes de uma língua vinculada diretamente ao Tupinambá. Note-se também que a ocorrência de um novo nome descritivo para a "banana" (ma'eapar "coisa recurvada") e a ausência do nome (comparativo) dado pelos Tupinambá a essa fruta importada ( pakóbá) parecem confirmar que os Avá não representam uma tradição Tupinambá ou de Língua Geral.

No subconjunto V pusemos o Kayabí, o Asuriní do Xingu e, tentativamente (por falta de dados), o Araweté. Esta associação do Asuriní do Xingu com o Kayabí se funda sobretudo no compartilhamento de ${ }^{*} p j \rightarrow s$ e de ${ }^{*} p w$ $\rightarrow f$ e na presença em Asuriní do Xingu do pronome ga "ele" (possivelmente também e "ela", mas traduzido por "ele" nos poucos exemplos disponíveis, Nicholson 1982), que corresponde ao Kayabí nga "ele" (e ẽẽ "ela"). Estas línguas são únicas em compartilhar essas três propriedades. ${ }^{*} p w \rightarrow f$ ocorre também em parte do subconjunto VI (no Tupí-Kawahíb, mas não no Parintintín nem no Apiaká), mas aí não ocorre ${ }^{*} p j \rightarrow s$. Os pronomes de $3^{\text {a }}$ pessoa, masculino, feminino e plural, ocorrem também no subconjunto VI, inclusive no Parintintín; mas, enquanto neste último há um só conjunto de pronomes de $3^{\mathrm{a}}$ pessoa ( $g$ a "ele", "ela", nga "eles, elas"), no Kayabí há dois conjuntos paralelos, um para os falantes de cada sexo ( $n g a$ "ele", ẽe "ela", ngã "eles, elas" usados por pessoas do sexo masculino e kĩa "ele", kỹna "ela", wã "eles, elas" usados por pessoas do sexo feminino). O subconjunto $\mathrm{V}$ difere do subconjunto IV não só pela inexistência neste de pronomes de $3^{\text {a }}$ pessoa com distinção de sexo e 
número e pelo diferente tratamento de * $p w(k w$ em IV, mas $f$ em V) e de * $j(t x$, $t s$, ou $z$ em IV, mas $d j$ em V), mas também por outras diferenças fonológicas (p. ex. o Kayabí e o Asuriní do Xingu não nasalizam as consoantes finais, ao contrário do que faz o Asuriní do Tocantins e, em parte, o Tapirapé: hakop "está quente", A. T. hakom: A. X. omonyk "ele sopra o fogo", A. T. omonyng; A. X. opotat "ele o quer", A. T. opotan, Tapirapé apatãn). Por outra parte, há alguns fenômenos fonológicos que são comuns especificamente ao Asuriní do Xingu (não ao Kayabí) e a línguas do subconjunto IV (p. ex., o abaixamento das vogais posteriores do PTG, mudando * $u$ em $o$ e mudando * $o$ em $a$; enquanto o abaixamento de * $u$ é geral nessas línguas, o de ${ }^{*} o \rightarrow a$ é geral no Tapirapé, mas se limita às sílabas acentuadas orais em Asuriní do Tocantins e Asuriní do Xingu: PTG *ajurú "papagaio", Tapirapé ãtxoró, A. T. atxoro-hoa, A. X. ajoro-a; PTG *pó "mão", Tapirapé pá, A. T. pa, A. X. pa; PTG *opotár "ele o quer", Tapirapé apatãn, A. T. opotan, A. X. opotat.

O subconjunto VI está constituído pelo Parintintín e pelo grupo de dialetos conhecido como Tupí-Kawahíb, Tupí do Machado ou Paranawát, assim como pelo Apiaká. O Parintintín é praticamente idêntico às línguas dos Júma e dos Tenharín. Na fonologia são muito semelhantes às línguas do subconjunto VI, mas o Apiaká apresenta $z$ em todas as ocorrências de * $j$ do PTG diante de vogal, e o Tupí-Kawahíb tem $f$ (bilabial) como reflexo do PTG * $p w$, ao passo que o Parintintín e o Apiaká têm kw: Tupí-Kawahíb kyféra "atrás" (Rondon e Faria 1948), Parintintín -akykwéri "ausência", oriundos de *-akypwéra e *-akypwéri, respectivamente; Tupí-Kawahíb fã "dedo" (Koch-Grünberg 1932), de * pwã (neste caso o Parintintín não tem kwã como, p. ex., o Guaraní, mas puã, provavelmente por influência da palavra pó "mão"). Em Tupí-Kawahíb também * $p$ muda em $f$ diante de u: fuká "rir" (Rondon e Faria 1948), de *puká, Parintintín puká.

O subconjunto VII difere dos subconjuntos V e VI especialmente por não ter desenvolvido a série de formas pronominais para a $3^{\mathrm{a}}$ pessoa, para distinguir masculino, feminino e plural. Fonologicamente são muito semelhantes, o que levou Nimuendajú (1948:313) a declarar que o Kayabí, o Apiaká, o Kawahíb e o Kamayurá diferem muito pouco. Entretanto, este último difere das línguas dos subconjuntos V e VI também no tratamento das sequências de fonemas * $p w$ e * $p j$ do PTG. No Kamayurá o * $p$ foi substituído por $h$ diante

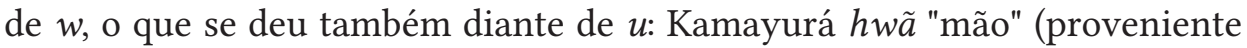
de "dedo"), hweráp "ressuscitar" (de "pweráb "recuperar-se"), hukú "comprido" (de *pukú) (cf. Parintintín puã, kweráp, pukú).

Por fim, o subconjunto VIII se distingue do subconjunto VII principalmente pela perda das consoantes finais e pela mudança de * $p w$ em $k w$. O Wayampí, o Wayampipukú e o Emérillon, embora estabelecidos no Amapá e na Guiana Francesa, migraram em tempos históricos para essa área ao norte 
do rio Amazonas, seguindo o vale do rio Jari; no século XVII achavam-se índios Wayampí ainda no baixo Xingu (Métraux 1927, Nimuendajú 1980). Os Urubú e Guajá, hoje no Maranhão, possivelmente se situaram mais a oeste nos séculos passados.

A perda das consoantes finais do PTG afeta essas línguas em diferentes graus. O Wayampí perdeu sistematicamente todas as consoantes finais, ao passo que o Wayampipukú conservou regularmente a consoante $r$ e perdeu as demais; já o Urubú perdeu em regra só a bilabial * $b$ e a velar * $n g$, tendo conservado todas as outras consoantes: PTG *kýb "piolho", Wayampí $k y$, Wayampipukú ky, Urubú ky; PTG akáng "cabeça", Wayampí ákã, Wayampipukú akã, Urubú akã; PTG *étým "fumo", Wayampí pétỹ, Wayampipukú péty, Urubú pytým; PTG *maníók "mandioca", Wayampí mani’o, Wayampipukú manío, Urubú mani'ók; PTG *pírwér "pele tirada do corpo", Wayampí píre "pele", Wayampipukú pírer, Urubú pirér.

Os subconjuntos acima delineados constituem não propriamente uma classificação interna da família linguística Tupí-Guaraní, mas antes um ensaio de discriminação de seções dessa família caracterizadas pelo compartilhamento de algumas propriedades linguísticas, as quais podem servir para diagnosticar o desmembramento de todo o conjunto de línguas Tupí-Guaraní visto como resultante histórico de uma protolíngua pré-histórica. Embora uma melhor caracterização desses subconjuntos requeira o recurso a maior número de propriedades linguísticas, gramaticais e lexicais, acredito que, enquanto não se faz um acúmulo maior de dados e não se elaboram mais detalhes, o quadro aqui delineado permite tanto entrever algumas afinidades maiores que podem ou não correlacionar-se com afinidades estabelecidas por critérios não linguísticos, quanto pôr em questão algumas hipóteses gerais ou particulares presentes na literatura sobre a história e a pré-história dos povos Tupí-Guaraní. Este é o caso de hipóteses tais como a da origem Karijó (Guaraní) dos Avá (Canoeiros) (Rivet 1924), a da origem Tamóyo (Tupinambá) dos Tapirapé (Kissenberth 1916, Métraux 1927), a da origem Tupinambá dos Kawahíb e dos Urubú (Kracke 197817), ou a da origem Guaraní dos Guaráyo (Métraux 1942:96) e dos Sirionó (Holmberg 1969:10-11).

Também as propostas de classificação das línguas e povos Tupí-Guaraní baseadas em hipotéticos movimentos migratórios pré-históricos, como as de Loukotka (1950) e Susnik (1975), podem ser confrontadas com o desmembramento em subconjuntos aqui sugerido e questionadas quanto a sua compatibilidade com a distribuição das propriedades linguísticas aqui consideradas.

\section{Referências}

Anchieta, Joseph de. 1595. Arte de grammatica da língua mais usada na costa do Brasil. Coimbra. (Tupinambá). 
Aragona, Alonso de. 1979. Breve introducción para aprender la lengua Guaraní. Presentación, edición y notas por Bartomeu Meliá. Ameríndia, Revue d'Ethnolinguistique Amérindienne, 4:23-61. (Guaraní Antigo).

Araujo, Antonio de. 1618. Catecismo na lingoa brasílica. Lisboa. (Tupinambá).

Bendor-Samuel, David. 1972. Hierarchical structures in Guajajara. Norman: Summer Institute of Linguistics. (Guajajára).

Betts, La Vera. 1981. Dicionário Parintintín-Português, Português-Parintintín. Brasília: Summer Institute of Linguistics. (Parintintín).

Boudin, Max H. 1963. O simbolismo verbal primitivo: análise estruturalista de um dialeto Tupi-Guaraní. Presidente Prudente: Faculdade de Filosofia, Ciências e Letras de Presidente Prudente. (Tembé).

1966. Dicionário de Tupi moderno (dialeto Tembé-ténêtéhar do alto Gurupi). São Paulo: Faculdade de Filosofia, Ciências e Letras de Presidente Prudente. (Tembé).

Bridgeman. Loraine I. 1961. Kaíwa (Guaraní) phonology. International fournal American Linguistics 27:329-34. (Kaiwá).

Coudreau, Henri. 1892. Vocabulaires méthodiques des langues Guayana, Aparai, Oyampí, Emérillon. Bibliothèque Linguistique Américaine 15. Paris. (Wayampí, Emérillon). 1897. Voyage au Tapajoz. Paris. (Apiaká).

Dobson, Rose. 1973. Notas sobre substantivos da Kayabí. Série Linguística 1:30-56. Brasília: Summer Institute of Linguistics. (Kayabí). 1976. Repetição em Kayabí. Série Linguística 5:83-105. Brasília: Summer Institute of Linguistics. (Kayabí).

Dooley, Robert A. 1982. Vocabulário do Guaraní: vocabulário básico do Guaraní contemporâneo (dialeto do Brasil). Brasília: Summer Institute of Linguistics. (Mbyá). Ehrenreich, Paul. 1895. Materialien zur Sprachenkunde Brasiliens, IV: Vocabulare der Guajajara und Anambé (Para). Zeitschrift für Ethnologie 27: 163-8. (Guajajára e Anambé).

Emmerich, Charlotte, e Ruth M. F. Monserrat. 1972. Sobre a fonologia da língua Awetí (Tupí). Boletim do Museu Nacional, nova série, Antropologia 25. Rio de Janeiro: Museu Nacional. (Awetí).

Faust, Norma. 1959. O sistema fonêmico do Kokama. Série Linguística Especial, Rio de Janeiro: Museu Nacional. (Kokáma).

1972. Gramática Cocama: lecciones para el aprendizaje del idioma cocama. Yarínacocha: Instituto Linguística de Verano. (Kokáma).

Firestone, Homer L. 1965. Description and classification Sirionó, a Tupí-Guaraní language. Haia: Mouton. (Sirionó, Horá, Chiriguáno).

Gregores, Ema, e Jorge A. Suárez. 1968. Colloquial Guaraní. Haia: Mouton. (Guaraní Paraguaio). 
Hanke, Wanda, Morris Swadesh e Aryon D. Rodrigues. 1958. Notas de fonologia Mekens. Miscellanea Paul River 2:187-217. México.

Harrison, Carl H. 1971. The morphophonology Asuriní words. Studies (D. Bendor-Samuel, ed.) 21-71. Norman: Summer Institute of Linguistics. (Asuriní do Tocantins). . 1975. Gramática Asuriní. Série Linguística 4. Brasília: Summer Institute of Linguistics. (Asuriní do Tocantins).

Hoeller, Alfredo. 1932a. Grammatik der Guarayo-Sprache. Guarayos (Dep. de S. Cruz de la Sierra)/Hall in Tirol. (Guaráyo).

. 1932b. Guarayo-Deutsches Wörterbuch. Guarayos (Dep. de S. Cruz de la Sierra) /Hall in Tirol. (Guaráyo).

Holmberg, Allan R. 1969. Nomads the long bow: the Sirionó Eastern Bolivia. Garden City: The Natural History Press.

Jensen, Cheryl. 1984. O desenvolvimento histórico da língua Wayampí, Dissertação de mestrado, Unicamp, Campinas. (Wayampí, Wayampipukú).

Kakumasu, James Y. 1976. Gramática gerativa preliminar da língua Urubú. Série Linguística 5:171-97. Brasília: Summer Institute of Linguistics. (Urubú).

Kissenberth, Wilhelm. 1916. Beitrag zur Kenntniss der Tapirapé-Indianer Baessler, Archiv VI, Heft 1/2. Leipzig/Berlim.

Koch-Grünberg, Theodor. 1932. Wörterlisten “Tupy”, Maué und Puruborá. Journal de la Société des Américanistes de Paris 24:31-50. (Tupí-Kawahíb).

Kracke, Waud H. 1978. Force and persuasion: leadership in an Amazonian society. Chicago: The University of Chicago Press.

Laraia, Roque de Barros, e Roberto da Malta. 1967. Índios e Castanheiros. São Paulo: Difusão Europeia do Livro. (Suruí).

Leite, Yonne F. 1977. Aspectos da fonologia e morfofonologia Tapirapé. Linguística VIII. Rio de Janeiro: Museu Nacional. (Tapirapé).

Lemle, M. 1971. Internal classification of the Tupí-Guaraní linguistic family, in D. Bendor-Samuel (ed.), Tupi Studies 1: 107-29. Norman: Summer Institute of Linguistics.

Léry, Jean de. 1578. Histoire d'un voyage fait en la terre du Brésil, autrement dite Amérique. La Rochelle. (Tupinambá).

Loukotka, Cestmir. 1950. Les langues de la famille Tupí-Guaraní. Boletim de Etnografia e Língua Tupí-Guaraní, Faculdade de Filosofia, Ciências e Letras. São Paulo: Universidade de São Paulo.

Magalhães, J. V. Couto de 1876. O selvagem: I, Curso de língua geral segundo Ollendorf compreendendo o texto original de lendas tupis. II, Origens, costumes, região selvagem... Rio de Janeiro. (Língua Geral Amazônica). . 1946. Viagem ao Araguaia. São Paulo: Editora Nacional. (Avá).

Martius. Karl Friedrich Ph. von. 1867. Beiträge zur Ethnographie und Sprachenkunde Amerika's zumal Brasiliens. Band Il: Zur Sprachenkunde. Leipzig. (Língua Geral Paulista). 
Mayntzhusen, F. C. 1919-1920, Die Sprache der Guayaki. Zeitschrift für Eigeborenen Sprachen 10:2-22. (Guayakí).

Métraux, Alfred. 1927. Migrations historiques des Tupi-Guarani. Journal de la Société des Américanistes de Paris 1911-45.

1942. The native tribes Eastern Bolivia and Western Matto Grosso. Handbook South American Indians, Smithsonian Institution, Bureau of American Ethnology, Bulletin 134. Washington, D. C.: Government Printing Office.

Monserrat, Ruth M. Fonini. 1976. Prefixos pessoais em Aweti. Linguística III. Rio de Janeiro: Museu Nacional. (Awetí).

Nicholson, Velda. 1978. Aspectos da língua Asuriní. Brasília: Summer Institute of Linguistics. (Asuriní do Tocantins).

1982. Breve estudo da língua Asuriní do Xingu. Ensaios linguísticos 5. Brasilia: Summer Institute of Linguistics. (Asuriní do Xingu, Asuriní do Tocantins).

Nimuendajú, Curt. 1914a. Die Sagen von der Erschaffung und Vernichtung der Welt als Grundlagen der Religion der Apapocúva-Guaraní. Zeitschrift für Ethnologie 46:284-403. (Ñandeva).

. 1914b. Vocabulários da Língua Geral do Brasil nos dialetos dos Manajé do rio Ararandéua, Tembé do rio Acará Pequeno e Turiwára do rio Acará Grande, Est. do Pará. Zeitschrift für Etnologie 46:615-18. (Amanayé, Tembé, Turiwára). 1932. Idiomas indígenas del Brasil. Revista del Instituto de Etnologia 2:543-618. Tucuman: Universidad Nacional de Tucuman. (Takunyapé). 1948. The Cayabí, Tapanyuna, and Apiacá. Handbook South American Indians (Julian H. Steward, cd.) (Smithsonian Institution, Bureau of American Ethnology, Bulletin 143) 3:307-20. Washington, D. C.: Government Printing Office. . 1980. Mapa etno-histórico do Brasil e regiões adjacentes. Brasília: Fundação Instituto Brasileiro de Geografia e Estatística.

Olson, Gary. 1978. Descrição preliminar de orações Wajapi. Ensaios Linguísticos 3. Brasília: Summer Institute of Linguistics. (Wayampí).

Olson, Roberta. 1978. Dicionário por tópicos nas línguas Oiampi (Waiapi)-Português. Ensaios Linguísticos 2. Brasília: Summer Institute of Linguistics. (Wayampí).

Rivet, Paul. 1924. Les indiens Canoeiros. Journal de la Société des Américanistes de Paris 16:169-82. (Avá).

Rodrigues, Aryon D. 1953. Morfologia do verbo Tupí. Letras 1:121-52. Curitiba. (Tupinambá).

. 1955. Morphologische Erscheinungen einer Indianersprache. Münchener-Stúdien zur Sprachwíssenschaft 7:79-88. (Tupinambá).

1958a. Die Klassifikation des Tupí-Sprachstammes. Proceedings of the Thirty-second International Congress of Americanists, Copenhagen 8-14 August 1956, pp. 679-84. Copenhague: Munskgaard. (Tradução: Classificação do tronco linguístico Tupí. Revista de Antropologia 12:99-104. 1964). 
. 1958b. Classification of Tupí-Guaraní. International Journal American Linguistics 241231-4.

. 1959. Phonologie der Tupinambá-Sprache. Dissertação de doutorado. Universidade de Hamburgo. (Tupinambá).

1966. Classificação da língua dos Cinta-Larga. Revista de Antropologia 14:2730.

. 1970. Línguas ameríndias. Grande Enciclopédia Delta-Larousse, pp. 4034-36. Rio de Janeiro: Delta.

. 1978. A língua dos índios Xetá como dialeto Guaraní. Cadernos de Estudos Linguístico 1:7-11. (Xetá).

. 1980. Tupí-Guaraní e Mundurukú: evidências lexicais e fonológicas de parentesco genético. Estudos Linguísticos (Anais de Seminários do GEL) 3:194-209.

Rodrigues, Daniele M. Grannier. 1974. Fonologia do Guaraní Antigo. Dissertação de mestrado. Unicamp, Campinas. (Guaraní Antigo).

Rondon, Cândido M. S. e João Barbosa de Faria. 1948. Glossário geral das tribos silvícolas de Mato Grosso e outras da Amazônia e do Norte da Brasil, Rio de Janeiro: Conselho Nacional de Proteção aos Índios. (Tupí-Kawahíb).

Ruiz (de Montoya), Antonio. 1639. Tesoro de la lengua Guaraní. Madri. (Guaraní Antigo).

.1640. Arte, y bocabulario de la lengua Guaraní. Madri. (Guaraní Antigo).

Saelzer, Meinke. 1976. Fonologia provisória da língua Kamayurá. Série Linguística 5:131-70. Brasília: Summer Institute of Linguistics. (Kamayurá).

Schermair, Anselmo. 1957. Vocabulário Sirionó-Castellano. Innsbrucker Beiträge zur Kulturwissenschaft, Sonderheft 5. Innsbruck. (Sirionó).

SCHMIDT, Max. 1937. Los Tapietés. Revista de la Sociedad Científica del Paraguay 4 (2): 36-67. (Tapieté).

. 1938. Los Chiriguanos e Izozós. Revista de la Sociedad Científica del Paraguay 4 (3): 1-115. (Chiriguáno, Izoceño).

Schuchard, Barbara. 1979. Nande Në: Gramática Guaraní para castellano hablantes. Santa Cruz de la Sierra. (Chiriguáno, Izoceño).

Silva, Alcionílio B. Alves da. 1961. Discoteca etno-linguístico-musical das tribos dos rios Uaupés, Içana e Cauaburi. São Paulo. (Língua Geral Amazônica).

Silva, Márcio Ferreira da, 1981. A fonologia segmental Kamayurá. Dissertação de Mestrado. UNICAMP, Campinas. (Kamayurá).

Staden, Hans. 1557. Wahraftig' Historia und Beschreibung eyner Landtschafft der Wilden, Nacketen, Grimmigen Menschfresser Leuthen, in der Newenwelt America gelegen... Marburg. (Tupinambá).

Stradelli, Ermano. 1929. Vocabularios da lingua geral portuguez-nhecngatú e Nheengatú-portuguez, precedidos de um esboço de grammatica nheênga-umbuê-sáua mirí e seguidos de contos em lingua geral Nheengatú poranduua. Revista do 
Instituto Histórico e Geográfico Brasileiro, tomo 104, vol. 158, pp. 9-768. (Língua Geral Amazônica).

Susnik, Branislava. 1975. Dispersión Tupi-Guaraní prehistórica: ensayo analítico. Asunción: Museo Etnográfico Andrés Barbero.

Tatevin, C. 1910. La langue Tapihiya dite Tupí ou Neengatu (Belle Langue): grammaire, dictionnaire et textes. Kaiserliche Akademie der Wissenschaften, Schriften der Sprachkommission, Band II. Viena. (Língua Geral Amazônica).

Tessmann, Günther. 1930. Die lndianer Nordost-Perus. Hamburg: Cram, De Gruyter \& Co. (Kokáma, Kokamíya, Omágua).

Vellard, J. 1934. Les Indiens Guayaki. Journal de la Société de: Américanistes de Paris 26:223-92, 27:175-244. (Guayakí). 